\title{
Desenvolvimento de máscaras de tecido e celulose para resposta emergencial à pandemia provocada pelo SARS-CoV-2
}

\author{
Development of tissue and cellulose masks for emergency response to the SARS-CoV-2 pandemic \\ Desarrollo de máscaras de tejido y celulosa para la respuesta de emergencia a la pandemia de SARS-CoV-2
}

\author{
Lisandra Rodrigues Risi'; Alexandre Barbosa de Oliveira"; Margarida Maria Rocha Bernardes"'; \\ Raquel de Souza Ramos ${ }^{\prime v}$; Elaine Cristina Valadares da Silva Moutinhov ${ }^{v}$, Aderson Campos Passos ${ }^{v 1}$
}

\begin{abstract}
RESUMO
Objetivo: desenvolver um modelo de máscara de tecido, com aplicação do elemento filtrante em celulose, para fins de utilização como barreira física segura para aerossóis, como estratégia de resposta emergencial à pandemia provocada pelo SARS-CoV-2. Método: pesquisa laboratorial realizada por meio de protótipos, testagens empíricas e análises e discussões junto a expertises. Resultados: a condução da pesquisa demonstrou que os aerossóis são retidos pela barreira física de celulose introduzida à estrutura das máscaras, o que motivou a segunda fase do estudo em unidade da Rede Brasileira de Laboratórios Analíticos de Saúde sobre a eficácia desses materiais. Conclusão: a confecção de máscaras de tecido é um fenômeno mundial importante e urgente frente à pandemia da COVID-19. Em função da crise de abastecimento e dos parâmetros ressaltados neste estudo, acredita-se que o uso desse equipamento possa ser estendido a setores não críticos de unidades de saúde, além da população em geral.
\end{abstract}

Descritores: Desastres; Infecções por Coronavírus; Equipamento de Proteção Individual; Máscaras.

\section{ABSTRACT}

Objective: to develop a model of fabric mask, with the application of a cellulose filter element, for use as a safe physical barrier for aerosols, as an emergency response strategy for the SARS-CoV-2 pandemic. Method: laboratory research carried out by means of prototypes, empirical tests and analyses, and discussions with experts. Results: the research demonstrated that aerosols are retained by the physical cellulose barrier introduced into the structure of the masks, which motivated the second phase of the study into the effectiveness of these materials at a unit of the Brazilian Analytical Health Laboratories Network. Conclusion: the making of fabric masks is an important and urgent worldwide phenomenon in tackling the COVID-19 pandemic. In view of the supply crisis and the parameters highlighted in this study, it is believed that the use of this equipment can be extended to non-critical sectors of health units, as well as to the general population.

Descriptors: Disasters; Coronavirus Infections; Personal Protective Equipment; Masks.

\section{RESUMEN}

Objetivo: desarrollar un modelo de mascarilla de tela, con la aplicación de un elemento filtrante de celulosa, para su uso como barrera física segura para aerosoles, como estrategia de respuesta de emergencia para la pandemia SARS-CoV-2. Método: investigación de laboratorio realizada mediante prototipos, pruebas y análisis empíricos y discusiones con expertos. Resultados: la investigación demostró que los aerosoles son retenidos por la barrera física de celulosa introducida en la estructura de las máscaras, lo que motivó la segunda fase del estudio sobre la efectividad de estos materiales en una unidad de la Red Brasileña de Laboratorios Analíticos de Salud. Conclusión: la fabricación de máscaras de tela es un fenómeno mundial importante y urgente para hacer frente a la pandemia de COVID-19. Ante la crisis de oferta y los parámetros resaltados en este estudio, se cree que el uso de este equipamiento puede extenderse a sectores no críticos de las unidades de salud, así como a la población en general.

Descriptores: Desastres; Infecciones por Coronavirus; Equipo de Protección Personal; Máscaras.

\section{INTRODUÇÃO}

A pandemia de Coronavirus Disease 2019 (COVID-19), doença infecciosa que vem vitimando de forma indiscriminada milhares de pessoas, levou as autoridades sanitárias mundiais a desenvolverem diretrizes para a sua prevenção não farmacológica, dentre as quais se destacam a higienização das mãos, a utilização do álcool a $70 \%$ em gel e o uso de máscaras ${ }^{1}$.

'Enfermeira. Doutoranda. Universidade Federal do Rio de Janeiro. Rio de Janeiro, Brasil. E-mail: lisandrarisi@gmail.com. ORCID: https://orcid.org/0000-0001-8436-5100 "Enfermeiro. Doutor. Professor Associado da Universidade Federal do Rio de Janeiro. Rio de Janeiro, Brasil. E-mail: alexbaroli@gmail.com. ORCID: http://orcid.org/0000-0003-4611-1200 IIEnfermeira. Doutora. Professora da Escola Superior de Guerra. Rio de Janeiro, Brasil. E-mail: margarida.rb.1502@gmail.com. ORCID: http://orcid.org/0000-0003-2849-413X IVEnfermeira. Doutora. Instituto Nacional de Câncer José Alencar Gomes da Silva. Rio de Janeiro, Brasil. E-mail: kakelramos@gmail.com. ORCID: https://orcid.org/0000-0001-7331-9715 vEnfermeira. Mestre. Analista de Ciência e Tecnologia do Ministério da Saúde. Brasília, DF, Brasil. E-mail: elaine.moutinho@saude.gov.br. ORCID: https://orcid.org/0000-0001-8580-5251 VIEngenheiro. Doutor. Professor do Instituto Militar de Engenharia. Rio de Janeiro, Brasil. E-mail: adersonncp@gmail.com. ORCID: https://orcid.org/0000-0002-6182-9360 
Desde o surgimento do surto pandêmico do novo coronavírus (2019-nCoV), impactos diretos e indiretos foram sentidos nos campos social, político, econômico, cultural e, sobretudo, da saúde. Com efeito, é grande a preocupação sobre o avanço desta doença ainda desconhecida, com alta transmissibilidade e gravidade clínica, que é acentuada pelos determinantes sociais da saúde, especialmente dos países em maior situação de vulnerabilidade e com governança precária ${ }^{2}$.

Em 30 de janeiro de 2020, a Organização Mundial da Saúde (OMS) declarou o surto como uma 'emergência de saúde pública de importância internacional' (ESPII), em razão da disseminação do coronavírus 2 (SARS-CoV-2) em diversos países ${ }^{3}$. Diante dessa situação e da necessidade de resposta coordenada entre as esferas municipal, estadual e federal de gestão do Sistema Único de Saúde (SUS), diversas medidas de prevenção, controle e contenção de riscos, danos e agravos à saúde pública passaram a ser estrategicamente desenvolvidas. Já em 03 de fevereiro de 2020 , o Ministério da Saúde do Brasil declarou a situação como uma 'emergência em saúde pública de importância nacional' (ESPIN), por meio da Portaria $\mathrm{n}^{0 .} 188^{4}$.

O primeiro caso de COVID-19 no Brasil foi oficialmente confirmado no dia 26 de fevereiro de 2020. Naquela ocasião, ainda era possível identificar casos individualmente e monitorar os contatos ${ }^{3}$. Em 11 de março a OMS caracterizou a COVID-19 como doença pandêmica. Já no dia 08 de agosto, o Brasil passou a contabilizar mais de 100.00 óbitos de cidadãos diante desse desastre biológico ${ }^{5,6}$.

A disseminação acelerada da infecção pelo coronavírus 2 (SARS-CoV-2) vem impactando a cadeia de suprimento global de equipamentos de proteção individual (EPI). A demanda gerada pelo aumento extraordinário do número de casos associada à desinformação, medo e pânico, levaram à compra e estocagem irracionais desses produtos. Esse uso generalizado e inadequado de EPI, como também a falta de previsão desses materiais para situações emergenciais, levaram a problemas de desabastecimento em muitos países, dada à limitada capacidade de expansão da produção global? .

Frente a esse quadro de risco iminente de desabastecimento de EPI, em especial de máscaras N95/PFF2, o Ministério da Saúde (MS) aprovou a Resolução de Diretoria Colegiada - RDC no 356, em 23 de março de $2020^{8}$, que trata de requisitos para a fabricação, importação e aquisição de dispositivos médicos identificados como prioritários para uso em serviços de saúde, em virtude da emergência de saúde pública internacional relacionada à COVID-19. Ademais, a publicação desta RDC envolveu a necessidade de se desenvolver produtos similares aos padronizados, com a finalidade operacional de minimizar os impactos causados pelo desabastecimento, de forma extraordinária e temporária ${ }^{8}$.

Em função dessa problemática de desabastecimento de EPI, e suas potenciais implicações para a qualidade e segurança da assistência nos estabelecimentos de saúde brasileiros, membros do Grupo de Ensino, Pesquisa e Extensão de Saúde em Emergências e Desastres, da Universidade Federal do Rio de Janeiro (GEPESED/UFRJ), em reunião científica de 9 de abril de 2020, discutiram a necessidade premente de se desenvolver estudos sobre possíveis tecnologias e estratégias de resposta emergencial frente a essa situação de desabastecimento de EPI. Assim, enquadrou-se esta perspectiva no âmbito do desenvolvimento da tese de doutoramento da primeira autora deste artigo, que versa sobre o desenvolvimento de tecnologias em saúde voltadas à logística em situações de emergências e desastres.

Com o amparo legal da Lei no 13.969, de 06 de fevereiro de 2020, e da Portaria no 327, de 24 de março de 2020, que estabelecem medidas de prevenção, cautela e redução de riscos de transmissão para o enfrentamento da COVID19 , as quais se referem à utilização de EPI, passou-se a atentar para o desenvolvimento de máscaras que, de forma segura e eficaz pudessem atender melhor a critérios de barreira e a impedir a disseminação no ambiente de gotículas pelas vias aéreas de seus usuários, a fim de garantir barreira física e prevenir novos casos da doença ${ }^{9,10}$.

Assim, iniciou-se processo de desenvolvimento deste estudo, com a produção de protótipos e testagens de máscaras de proteção individual, confeccionadas em tecido de algodão e com barreira extra de proteção em celulose, quanto a padrões de segurança, qualidade e eficácia contra a contaminação por coronavírus 2 (SARS-CoV-2).

Além da preocupação com tais padrões, a realização deste estudo também envolve potenciais contribuições para a proteção ecológica, uma vez que as máscaras produzidas em tecido e o elemento filtrante em celulose podem cumprir duas finalidades socioambientais: a de reuso (máscara de tecido) e a de reciclagem (elemento filtrante). Trata-se, pois, de um contraponto em relação à utilização de materiais médicos hospitalares descartáveis que, usualmente, tem como destinação final a incineração ou mesmo contaminação do ambiente pelo descarte inapropriado.

Diante desse cenário, teve-se como objetivo desenvolver um modelo de máscara de tecido, com aplicação do elemento filtrante em celulose, para fins de utilização como barreira física segura para aerossóis, como estratégia de resposta emergencial à pandemia de COVID-19. 


\section{MÉTOdo}

Trata-se de uma pesquisa laboratorial, que foi determinada pelo desenvolvimento de um modelo de máscara de tecido com a inserção de elemento filtrante em celulose. Para análise deste objeto de estudo foram selecionadas variáveis capazes de influenciá-lo, e definidas as formas de controle e de observação dos efeitos que cada variável pudesse produzir ao objeto ${ }^{11}$.

A equipe contou com a participação de membros de diferentes instituições de pesquisa e assistência, da Universidade do Estado do Rio de Janeiro, da Universidade Federal do Rio de Janeiro, da Escola Superior de Guerra, do Instituto Militar de Engenharia, do Instituto Nacional do Câncer, do município do Rio de Janeiro, e do Ministério da Saúde, de Brasília (Distrito Federal), inclusive de artesãs voluntárias que confeccionaram os protótipos.

A pesquisa foi dividida em duas fases distintas. Uma voltada para estudos preliminares, análise de documentação oficial, produção propriamente dita das máscaras, testagens empíricas e divulgação pública; e outra para testagens em laboratórios e validação das máscaras. Ressalta-se que este artigo refere-se aos resultados da primeira fase da pesquisa.

As máscaras foram elaboradas em consonância com as orientações para produção de máscaras de tecido em algodão, que foram disponibilizadas pelo Ministério da Saúde por meio da Nota informativa $n^{\circ} 3 / 2020$ CGGAP/DESF/SAPS/MS e a Nota técnica GVIMS/GGTES/ANVISA n 4/2020 com as orientações para a população em geral e serviços de saúde, que convergem em medidas de prevenção e controle que devem ser adotadas durante a assistência aos casos suspeitos ou confirmados de infecção pelo novo coronavírus (SARS-CoV-2) ${ }^{12}$.

Os pesquisadores desenvolveram três Testes empíricos, cujos resultados foram socializados, de forma pública, por meio de redes sociais, o que motivou o desenvolvimento da segunda fase deste estudo. O vídeo está disponível no endereço eletrônico: https://youtu.be/vhoRRwB7pHA.

Após a produção dos protótipos e a realização dos Testes empíricos, foram desenvolvidas análises e discussões junto a expertises da área de produção tecnológica do Instituto Militar de Engenharia do Exército, unidade esta vinculada ao Ministério da Defesa. Após, as máscaras foram enquadradas às normas da Associação Brasileira de Normas Técnicas - ABNT por meio da prática recomendada publicada em 17 de abril de 2020 (ABNT PR1002:2020), no que diz respeito às diretrizes e normativas recomendadas para confecção e composição deste tipo de $\mathrm{EPI}^{13 .}$

Após a confecção dos protótipos, foram encaminhadas amostras das máscaras a um laboratório pertencente à Rede Brasileira de Laboratórios Analíticos em Saúde (REBLAS), em conformidade com o que é previsto pela Agência Nacional de Vigilância Sanitária - Anvisa, por meio da RDC 12 de 16 de fevereiro de $2012^{14}$.

Para esta fase foi solicitado e orçado os ensaios para avaliar a permeabilidade do ar nas máscaras de tecido de algodão sem e com o elemento filtrante em celulose, no laboratório de física vinculado à rede REBLAS ${ }^{\circ}$, que é credenciado pela Anvisa e pelo Instituto Nacional de Metrologia, Qualidade e Tecnologia - Inmetro, sendo este último uma autarquia federal vinculada à Secretaria Especial de Produtividade, Emprego e Competitividade, do Ministério da Economia.

Para os ensaios de permeabilidade, os pesquisadores forneceram ao laboratório para os ensaios, 10 (dez) unidades de cada máscara, sendo elas confeccionadas em tecido de algodão com dupla camada e clipe nasal com fenda. Foram também encaminhadas no mesmo quantitativo as máscaras industrializadas: cirúrgicas descartáveis, modelo N95/PFF2 e máscara em tecido duplo de malha de algodão, totalizando 05 (cinco) ensaios. Os protótipos das máscaras desenvolvidos pelos pesquisadores (máscaras de tecido em algodão com dupla camada e clipe nasal com fenda) tiveram suas análises em dois momentos, por meio da medida de permeabilidade do ar sem e com o elemento filtrante de celulose.

\section{Materiais e matérias primas utilizadas}

O tecido $100 \%$ algodão foi o material empregado para a confecção das máscaras, sendo este o mais indicado pela formação de suas tramas e calandragem, que suportam processos de lavagem com produtos saneantes mais abrasivos. Esse tipo de material tem as seguintes gramaturas: 90 a 110, 120 a 130 e 160 a 210 . Em geral são toleradas misturas na sua composição: $90 \%$ de algodão com $10 \%$ de elastano, $92 \%$ de algodão com $8 \%$ de elastano, e $96 \%$ de algodão com $4 \%$ de elastano ${ }^{16}$. O uso de outros tipos de tecidos, como o poliéster puro e outros sintéticos, não são recomendados para produção de máscaras na qualidade de EPI.

O componente que diferencia o modelo do protótipo defendido por este estudo é a inserção da barreira filtrante e biodegradável composta por celulose, que potencializa a segurança dos usuários deste equipamento de proteção. Sabe-se que a respiração elimina gotículas, calor e umidade, que vão para o meio ambiente, onde pode (ou não) existir a presença do vírus. Nesse sentido, a aplicabilidade da barreira de celulose, que é inserida no centro da máscara de tecido duplo, tem potencial para contribuir para a retenção de partículas. 
Essa matéria-prima é composta por $100 \%$ de fibra celulósica (conhecida como papel crepado), com dupla prensagem na sua confecção. A celulose é um material orgânico extraído principalmente da madeira ou da palha de milho, biodegradável/sustentável, que não causa danos à saúde humana e ambiental. Estudos apontam que a celulose pode ser obtida de qualquer vegetal, sendo também evidenciados processos de obtenção de celulose e produção de papel branqueado a partir do capim grachiaria (Brachiaria decumbens), espécie de gramínea muito comum no Brasil ${ }^{15,16}$.

O fluxograma com as etapas da construção da máscara de tecido em algodão com fenda é apresentado na Figura 1.

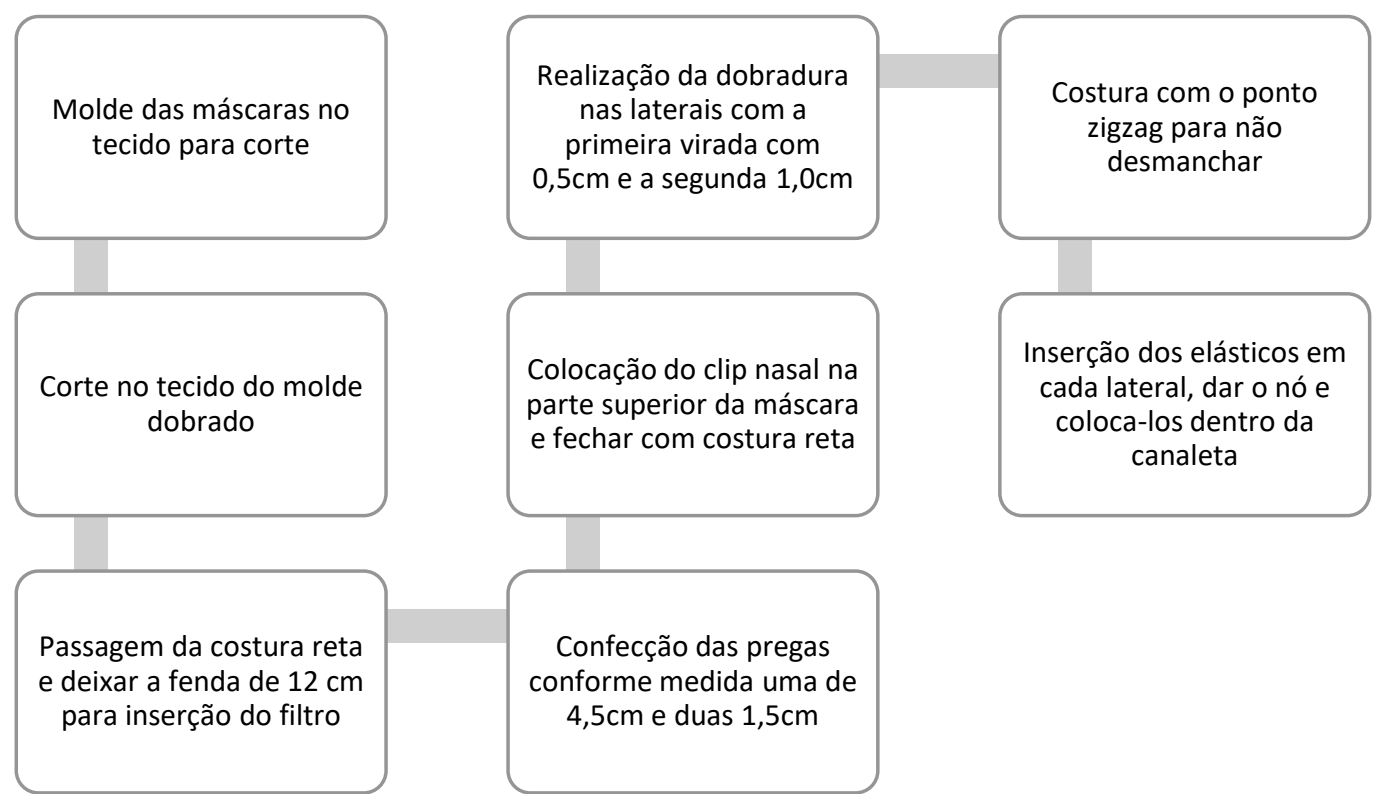

FIGURA 1: Fluxograma com as etapas da construção da máscara de tecido em algodão com fenda. Rio de Janeiro, Brasil, 2020

Os protótipos de máscara de tecido de algodão desenvolvidos foram designados pelos pesquisadores como "LisLu20". Ressalta-se que, à luz da Convenção de Berna, este estudo foi registrado em 23 de abril de 2020, para fins de proteção das obras literárias e artísticas, com o Registro no $712144782^{17}$.

\section{RESULTADOS E DISCUSSÃO}

Neste estudo partiu-se da premissa de que a inserção do elemento filtrante em celulose inserido, nas máscaras produzidas e testadas, é um aspecto positivo para a segurança. Em geral, este elemento é de fácil acesso e de baixo custo, o que pode trazer potenciais repercussões para a redução da dependência de importação desse tipo de equipamento. Com efeito, o problema de autossuficiência de produção de EPI é um dos grandes desafios enfrentados por diversos países, para a resposta emergencial à pandemia de COVID-19, inclusive no Brasil.

É relevante o fato de que o Brasil é o quarto maior produtor de celulose do mundo. Em 2016, o Brasil produziu 17,1 milhões de toneladas de celulose e 9,5 milhões de toneladas de papel. Geralmente, a celulose produzida no Brasil é derivada de florestas plantadas de eucaliptos e pinus ${ }^{17}$.

Considera-se ainda que a celulose, com sua estrutura fibrosa biodegradável e úmida, possui a capacidade de retenção de líquidos e partículas, em função do estabelecimento de múltiplas pontes de hidrogênio, o que as torna insolúveis (impenetráveis à água) ${ }^{18}$.

Outro aspecto tem a ver com o descarte ecologicamente apropriado do material infectado, pois o descarte incorreto tende a provocar danos ao meio ambiente. Após o uso da máscara aqui indicada, a mesma deve ser lavada junto com o filtro de celulose, com água e sabão. Assim, a máscara é reutilizada, e o filtro biodegradável é descartado de modo mais seguro.

Ressalta-se que, o documento elaborado pela OMS e traduzido para o idioma português pela OPAS, discute o uso de máscara para população em geral, em ambientes em que o distanciamento físico não é possível e existe um maior risco de infecção e/ou desfechos negativos, principalmente para populações vulneráveis (indivíduos com idade $\geq 60$ 
anos, indivíduos com comorbidades de base, como doença cardiovascular ou diabetes, doença pulmonar crônica, câncer, doença cerebrovascular, imunossupressão) que deverão usar máscara cirúrgica e não a de tecido ${ }^{19}$.

\section{Resultados dos Testes preliminares das máscaras}

A Figura 2 descreve o desenvolvimento dos três Testes empíricos e seus respectivos resultados.

\begin{tabular}{|c|c|c|c|}
\hline Testagem & Descrição & Ações desenvolvidas & Resultados dos Testes empíricos \\
\hline $\begin{array}{c}\text { Testagem } \\
1\end{array}$ & $\begin{array}{l}\text { Análise da barreira física } \\
\text { conferida pelos } \\
\text { protótipos SEM filtro de } \\
\text { celulose }\end{array}$ & $\begin{array}{l}\text { a) posicionamento da máscara na } \\
\text { face, seguindo recomendações } \\
\text { técnicas da RDC } 356 / 2020 ; \\
\text { b) acendimento de pequeno ponto } \\
\text { de chama; } \\
\text { c) posicionamento da chama a uma } \\
\text { distância de } 15 \mathrm{~cm} \text { da face do usuário } \\
\text { da máscara; } \\
\text { d) sopro de intensidade leve, } \\
\text { moderada e forte pelo usuário. } \\
\text { e) aspersão de spray de dentro para } \\
\text { fora da máscara, com intensidade } \\
\text { forte. }\end{array}$ & $\begin{array}{l}\text { e) aspersão dos aerossóis do spray PASSAM } \\
\text { com facilidade pela máscara, visivelmente } \\
\text { sem o elemento filtrante (celulose) }\end{array}$ \\
\hline $\begin{array}{l}\text { Testagem } \\
\quad 2\end{array}$ & $\begin{array}{l}\text { Análise da barreira física } \\
\text { conferida pelos } \\
\text { protótipos COM filtro de } \\
\text { celulose }\end{array}$ & $\begin{array}{l}\text { a) posicionamento da celulose no } \\
\text { interior da máscara de tecido; } \\
\text { b) posicionamento da máscara na } \\
\text { face, seguindo recomendações } \\
\text { técnicas da RDC } 356 / 2020 ; \\
\text { c) acendimento de pequeno ponto de } \\
\text { chama; } \\
\text { d) posicionamento da chama a uma } \\
\text { distância de } 15 \mathrm{~cm} \text { da face do usuário } \\
\text { da máscara; } \\
\text { e) sopro de intensidade leve, } \\
\text { moderada e forte pelo usuário. }\end{array}$ & $\begin{array}{l}\text { a-e) a chama do fósforo ou do isqueiro NÃO } \\
\text { se apagam }\end{array}$ \\
\hline $\begin{array}{l}\text { Testagem } \\
\mathbf{3}\end{array}$ & $\begin{array}{l}\text { Análise da barreira física } \\
\text { conferida pelos } \\
\text { protótipos COM filtro de } \\
\text { celulose }\end{array}$ & $\begin{array}{l}\text { a) posicionamento da máscara na } \\
\text { face do usuário conforme } \\
\text { recomendações técnicas da RDC } \\
356 / 2020 ; \\
\text { b) aspersão de spray de dentro para } \\
\text { fora da máscara, com intensidade } \\
\text { forte. }\end{array}$ & $\begin{array}{l}\text { a-b) aspersão dos aerossóis do spray NÃO } \\
\text { passam através da máscara, visivelmente } \\
\text { COM o elemento filtrante (celulose) }\end{array}$ \\
\hline
\end{tabular}

FIGURA 2: Testagens preliminares. Rio de Janeiro, Brasil, 2020.

O Teste 1, que analisou a barreira física conferida pelos protótipos sem filtro de celulose, evidenciou que, de forma nítida e recorrente, a chama foi apagada, demonstrando que os aerossóis expelidos pelos usuários da máscara não foram impedidos de serem transpassados. Posteriormente, nos outros Testes 2 e 3 , foram acrescentadas folhas de celulose. No Teste 2, o spray espargido na máscara, com forte intensidade, não a transpassou. E, no Teste 3, os sopros dados pelos próprios usuários, com forte intensidade, não foram capazes de apagar a chama a uma distância de $15 \mathrm{~cm}$ da face. Assim, esses Testes comprovaram, empiricamente, que os aerossóis expirados ficaram retidos pela barreira física introduzida.

Por meio de tais resultados preliminares, pressupõe-se que as medidas individuais de proteção contidas nesta proposta têm potencial impacto positivo no controle do avanço da pandemia de COVID-19. Tal uso necessariamente precisa ser combinado às medidas preventivas preconizadas pela OMS e pela Organização Pan-Americana de Saúde $(\mathrm{OPAS})^{18,19}$, como higienização das mãos com água e sabão ou preparação alcoólica a $70 \%$, medidas de segurança e de higiene respiratória da tosse, como cobrir nariz e boca com o cotovelo fletido, uso de lenço descartável, o qual deve ser imediatamente descartado após o uso e realizada novamente a higiene das mãos, além de se evitar tocas as mucosas de olhos, nariz e boca, publicada em 05 de junho de $2020^{19}$. 


\section{Produção, indicação e utilização das máscaras}

A máscara de tecido em algodão duplo e o elemento filtrante em celulose entremeada, compõem o modelo “LisLu20" em análise. O modelo está demonstrado nas Figuras 3 e 4.

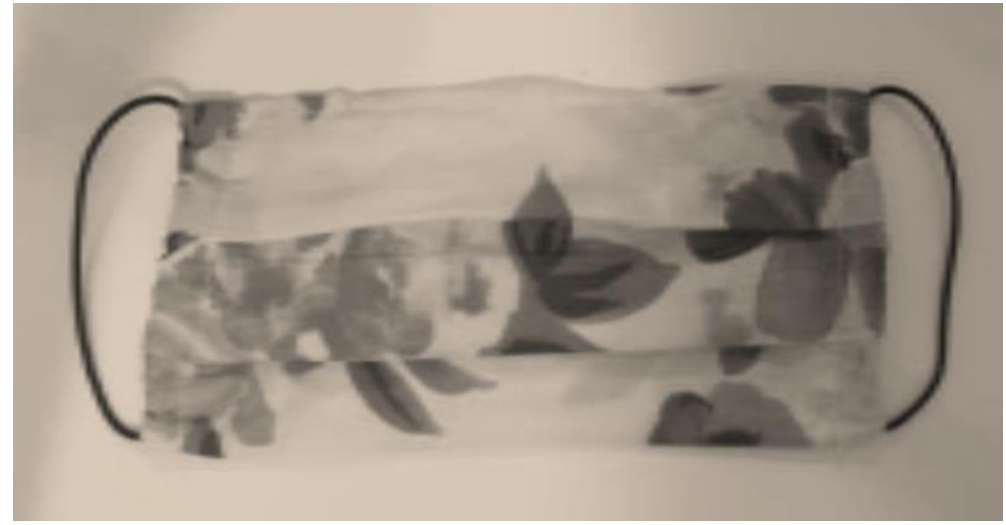

FIGURA 3: Lislu20 ${ }^{\circledast}$ (visão frontal). Rio de Janeiro, Brasil, 2020.

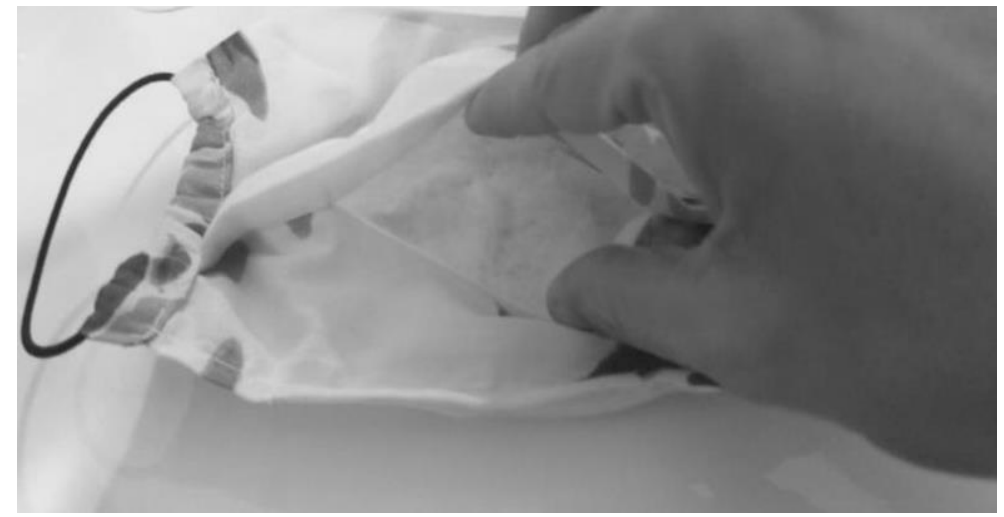

FIGURA 4: LisLu20 ${ }^{\circledR}$ (abertura no verso para colocação do material em celulose). Rio de Janeiro, Brasil, 2020.

Adverte-se que o uso de máscaras de tecido, confeccionadas com materiais comuns e de baixo custo, tem sua indicação reconhecida como medida voluntária e efetiva de controle do avanço da pandemia de COVID-19.

Em virtude do desabastecimento de setores hospitalares específicos, o que ultimamente vem sendo constantemente noticiado pela mídia e denunciado por sindicatos e profissionais de saúde, há que se pensar nas possibilidades de se estender o uso das máscaras desenvolvidas neste estudo para os profissionais, que atuam nos setores não-críticos das unidades de saúde sem a permanência de pacientes, como porta de entradas, elevadores, almoxarifados, áreas administrativas, centrais de material e esterilização.

Para a produção de máscaras aqui descritas e maior garantia de eficácia no que diz respeito à barreira física, recomenda-se que as mesmas devam ser confeccionadas com pelo menos duas camadas de pano (100\% algodão, tricoline), e desenhadas com elásticos ou tiras para amarrar acima das orelhas e abaixo da nuca.

Para potencializar as medidas de prevenção, é indispensável higienizar corretamente as mãos, fazer o uso individual das máscaras, não compartilhando-as nem mesmo entre familiares. Recomenda-se ainda que cada pessoa tenha ao menos cinco máscaras de uso individual. E, se necessário sair de casa, levar sempre máscaras sobressalentes em um saco plástico ${ }^{20}$. 
Para a utilização correta da máscara é preciso cobrir totalmente a boca e o nariz, ajustando-a ao rosto, sem deixar espaços nas laterais, e evitar ao máximo tocar ou ajustar a máscara depois de colocá-la. Caso fique úmida, fazse necessária a troca.

Quanto à higienização, deve ser lavada pelo próprio usuário. Dessa forma, ao chegar em casa, antes da retirada da máscara, deve-se lavar bem as mãos, secando-as bem, remover a máscara pelo laço ou elástico da lateral do rosto, evitando tocar na parte dianteira. Em seguida, deve-se lavar a máscara com sabão de coco ou água sanitária diluída, deixando-a de molho por cerca de 30 (trinta) minutos. Após isso, enxaguar e colocar para secar em local arejado e ventilado.

Enfim, após os trâmites de testagem da fase 2 deste estudo será disponibilizado o molde desenvolvido, com instruções precisas para a confecção das máscaras, a fim de ampliar o acesso desta tecnologia e de se contribuir com o processo emergencial de diminuição dos potenciais riscos de avanço deste desastre biológico. Isso pode, inclusive, agregar rentabilidade financeira e inclusão social para as pessoas que se dispuserem a produzi-la pois, nas situações de alteração ou de interrupção das medidas de afastamento social nos municípios e estados brasileiros, a demanda da população por máscaras de tecido tende a aumentar sobremaneira.

Compreende-se, desse modo, que a tecnologia aqui proposta guarda fortes nexos com o desenvolvimento de equipamentos servíveis para o cuidado humano e ambiental, uma vez que a disponibilidade de itens com alta eficácia e em quantidade suficiente, especialmente a pessoas e grupos mais vulneráveis e empobrecidos, pode permitir que as medidas a serem tomadas pós-crise sejam mais efetivas, e que dias melhores cheguem logo.

\section{CONCLUSÃO}

A confecção de máscaras de tecido é um fenômeno mundial necessário e urgente. Recentemente, o Ministério da Saúde do Brasil mobilizou a população por meio de ampla campanha de produção e uso de máscaras de pano, considerando ser este um EPI simples, sem dificuldade na produção e aliado essencial no combate à propagação da COVID-19.

Uma vez que o estudo comprove a eficiência da barreira implementada, por meio do tecido de algodão duplo e da celulose, acredita-se que se possa estender emergencialmente seu uso para setores não críticos de algumas unidades de saúde, como portas de entrada, triagens, centros de material e esterilização, caso a crise de desabastecimento de EPI não seja resolvida a curto prazo. Entretanto, os demais setores deverão continuar a fazer uso das máscaras cirúrgicas ou máscaras N95/PFF2. Esses itens são essenciais à segurança da assistência, e devem ter a reserva de mercado direcionada para uso exclusivo de profissionais de saúde e outros socorristas, que atuam nas linhas de frente da resposta à pandemia.

Considera-se, ainda, a necessidade de se diminuir potenciais impactos ambientais relacionados ao descarte indevido de máscaras. Assim, o modelo proposto constitui-se de material reutilizável e reciclável com descarte apropriado, em lixo doméstico, sem causar contágios e danos ambientais. Tal medida pode contribuir para o maior controle da doença e para a segurança dos usuários e das pessoas com quem mantém proximidade.

A publicação deste trabalho tem a intenção de trazer contribuições para saúde pública no atual contexto da Pandemia, e a comunicação de possibilidades do uso de máscara de tecido com segurança e validação. Por fim, esclarece-se que a segunda fase deste estudo está em desenvolvimento e contempla Testes em laboratórios de Física e Microbiologia certificados, os quais irão dar suporte para se caracterizar a segurança, qualidade e eficácia das máscaras aqui descritas.

\section{REFERÊNCIAS}

1. Garcia LP, Duarte E. Nonpharmaceutical interventions for tackling the COVID-19 epidemic in Brazil. Epidemiol. Serv. Saúde [Internet], 2020 [cited 2020 May 06]; 29(2): e2020222. DOI: https://doi.org/10.5123/s1679-49742020000200009

2. Freitas ARR, Napimoga M, Donalisio MR. Assessing the severity of COVID-19. Rev. Epidemiol. Serv. Saúde [Internet], 2020 [cited 2020 Apr 19]; 29(2):e2020119. DOI: https://doi.org/10.5123/s1679-49742020000200008

3. Ministério da Saúde (Br). Secretaria de Vigilância em Saúde. Centro de Operações de Emergência em Saúde Púbica/Doença pelo Coronavírus 19 (COE-COVID19). Boletim Epidemiológico COE № 02. Brasília (DF): Ministério da Saúde; 2020. [cited 2020 May 08]. Available from: https://portalarquivos.saude.gov.br/images/pdf/2020/fevereiro/13/BoletimepidemiologicoCOEcoronaSVS-13fev20.pdf

4. Ministério da Saúde (Br). Gabinete do Ministro. Portaria no 188, de 03 de fevereiro de 2020. Declara Emergência em Saúde Pública de Importância Nacional (ESPIN) em decorrência da Infecção Humana pelo novo Coronavírus (2019-nCoV). Brasília (DF): Ministério da Saúde; 2020. [cited 2020 May 08]. Available from: http://www.in.gov.br/en/web/dou/-/portaria-n-188-de-3-defevereiro-de-2020-241408388 
5. Ministério da Saúde (Br). Secretaria de Vigilância em Saúde, Departamento de Informática do SUS. Coronavírus Brasil: Painel Geral Coronavírus. Brasília (DF): Ministério da Saúde; 2020. [cited 2020 May 08]. Available from: https://covid.saude.gov.br/

6. World Health Organization. WHO Coronavirus Disease (COVID-19) Dashboard. Geneva (Switzerland): WHO; 2020. [cited 2020 May 08]. Available from: https://covid19.who.int/

7. World Health Organization. Rational use of personal protective equipment for coronavirus disease (COVID-19): interim guidance. Geneva (Switzerland): WHO; 2020. [cited 2020 May 08]. Available from: https://apps.who.int/iris/bitstream/handle/10665/331215/WHO-2019-nCov-IPCPPE_use-2020.1-eng.pdf

8. Ministério da Saúde (Br). Resolução de Diretoria Colegiada - RDC no 356, de 23 de março de 2020. Dispõe, de forma extraordinária e temporária, sobre os requisitos para a fabricação, importação e aquisição de dispositivos médicos identifica dos como prioritários para uso em serviços de saúde, em virtude da emergência de saúde pública internacional relacionada ao SARS-CoV-n. Brasília (DF): Ministério da Saúde; 2020. [cited 2020 May 08]. Available from: http://portal.anvisa.gov.br/documents/10181/5809525/RDC_356_2020_.pdf/0655c7ae-8c47-4be9-bf0d-4c7b8df03e4e

9. Ministério da Saúde (Br). Lei no 13.969, de 06 de fevereiro de 2020. Dispõe sobre as medidas para enfrentamento da emergência de saúde pública de importância internacional decorrente do coronavírus responsável pelo surto de 2019. Brasília (DF): Ministério da Saúde; 2020. [cited 2020 May 08]. Available from: http://www.in.gov.br/en/web/dou/-/lei-n-13.979-de-6de-fevereiro-de-2020-242078735

10. Ministério da Saúde (Br). Portaria no 337, de 24 de março de 2020. Dispõe acerca de medidas para o enfrentamento da emergência de saúde pública de importância internacional decorrente do coronavírus, COVID-19, no âmbito do Sistema Único de Assistência Social. Brasília (DF): Ministério da Saúde; 2020. [cited 2020 May 08]. Available from: http://www.in.gov.br/en/web/dou/-/portaria-n-337-de-24-de-marco-de-2020-249619485

11. Polit DF, Beck CT, organizadores. Fundamentos de Pesquisa em Enfermagem: avaliação de evidências para a prática da Enfermagem. 7a ed. Porto Alegre (RS): Artmed; 2011.

12. Ministério da Saúde (Br). Nota Informativa № 3/2020-CGGAP/DESF/SAPS/MS. Brasília (DF): Ministério da Saúde; 2020. [cited 2020 May 08]. Available from: https://www.saude.gov.br/images/pdf/2020/April/04/1586014047102-Nota-Informativa.pdf

13. Associação Brasileira de Normas Técnicas. Práticas Recomendadas PR 1002:2020 - Máscaras de Proteção Respiratória de uso não profissional - Guia de requisitos básicos para métodos de ensaio, confecção e uso. São Paulo: ABNT; 2020. [cited 2020 May 08]. Available from: https://www.abntcatalogo.com.br/norma.aspx?ID=442968

14. Ministério da Saúde (Br). Resolução de Diretoria Colegiada no 12, de 16 de fevereiro de 2012. Dispõe sobre a Rede Brasileira de Laboratórios Analíticos em Saúde (REBLAS). Brasília (DF): Ministério da Saúde; 2012. [cited 2020 May 08]. Available from: https://bvsms.saude.gov.br/bvs/saudelegis/anvisa/2012/res0012_16_02_2012.html

15. Agência Nacional de Vigilância Sanitária (Br). Orientações gerais - Máscaras faciais de uso não profissional. Brasília (DF): Anvisa; 2020. Available from: http://portal.anvisa.gov.br/documents/219201/4340788/NT+M\%C3\%A1scaras.pdf/bf430184-8550-42cba975-1d5e1c5a10f7

16. Senna AM, Menezes JB, Batista FVS, Melissa GS, Ribeiro GS, Gocoy MO. Obtenção de Celulose e Produção de Papel Branqueado. Quím. nova esc. [Internet], 2018 [cited 2020 May 08]; 40(2): 116-120. DOI: http://dx.doi.org/10.21577/01048899.20160112

17. Indústria Brasileira de Árvores. Estatísticas da Indústria Brasileira de Árvores. Brasília (DF): Ibá; 2017. [cited 2020 May 08]. Available from: http://iba.org/images/shared/Cenarios/Cenarios_Jan_2017.pdf

18. Organização Pan-Americana de Saúde. COVID-19: Materiais de comunicação. Washington (DC): OPAS; 2020. [cited 2020 May 08]. Available from: https://www.paho.org/bra/index.php?option=com_content\&view=article\&id=6130:covid-19-materiais-decomunicacao\&Itemid=0\#atividade

19. World Health Organization. Advice on the use of masks in the context of COVID-19: interim guidance, 5 June 2020. Geneva (Switzerland): WIPO; 2020. [cited 2020 May 08]. Available from: https://apps.who.int/iris/handle/10665/332293

20. World Intellectual Property Organization. Berne Convention for the Protection of Literary and Artistic Works. Geneva (Switzerland): WIPO; 1979. [cited 2020 May 08]. Available from: https://wipolex.wipo.int/en/text/283693 